\title{
Two-way shape memory-clips for colonic anastomosis
}

\author{
H. Morawiec ${ }^{\text {a, } 1}$, Z. Lekston ${ }^{1}$, P. Lampe ${ }^{2}$, K. Kuśnierz ${ }^{2}$, D. Zhavoronkov ${ }^{2}$ \\ ${ }^{1}$ Institute of Materials Science, University of Silesia, 40-007 Katowice, Bankowa 12, Poland \\ ${ }^{2}$ Department of Gastrointestinal Surgery, Medical University of Silesia, 40-752 Katowice, Medyków 14, Poland
}

\begin{abstract}
The compression anastomosis clip (CAC) is an elliptic shape double-ring device produced from nickeltitanium shape memory alloy. Until now the CAC works basing on the one-way shape memory effect. The aim of presenting studies was finding out the technology of two-way shape memory (TWSME) clips formation which should fulfil the requirements for clinical application. The clips were formed by wires of an alloy with $51.02 \mathrm{at} . \% \mathrm{Ni}-$ balance Ti. The best value of the TWME and uniform compression force of the clips was achieved by combining deformation, constrained aging and thermomechanical cycling.
\end{abstract}

\section{Introduction}

Since a century surgeons have attempted to produce a device which should enable them to perform a competent anastomosis both quickly and cost effectively. For a long time hand suture has been used. Current routine surgery practice deals with using staplers for mechanical suture to create a uniform anastomosis [1]. Sutureless anastomosis using the shape memory clips ensure anastomosis that is highly resistant to leakage which may cause sepsis.

The new anastomosis method based on compression clip which operate on the basis of one-way shape memory effect was studied and described in [2-5]. A new concept concern the possibility of using the superelastic effect in clips for gastrointestinal tract anastomosis was performed in [6]. The analysis of the actual state of art and own broad experience in experimenmtal and clinical research of the anastomosis with shape memory and superelastic clips is given in [7].

The aim of this paper was to find out the technology of clips formation with a TWSME which should fulfil the requirements for clinical application in anastomosis of gastrointestinal procedure.

\section{Experimental}

The compression anastomosis clip (CAC) is an elliptic shape double-coil ring device produced from wire of nickel-titanium shape memory alloy. The chemical analysis and characteristic temperatures of the studied alloys used for clips with one-way shape memory and TWSME are given in table 1.

Table 1. Chemical composition and characteristic temperatures of the studied alloys used for clips

\begin{tabular}{|c|c|c|c|c|c|c|c|c|}
\hline Alloy & $\begin{array}{c}\mathrm{Ni} \\
{[\mathrm{at} \%]}\end{array}$ & $\begin{array}{c}\mathrm{Ti} \\
{[\text { at \%] }}\end{array}$ & $\begin{array}{c}\mathrm{Al} \\
{[\mathrm{at} \%]}\end{array}$ & $\begin{array}{c}\mathrm{Si} \\
\text { at \%] }\end{array}$ & $\begin{array}{c}\mathrm{M}_{\mathrm{s}} \\
{\left[{ }^{\circ} \mathrm{C}\right]}\end{array}$ & $\begin{array}{c}\mathrm{A}_{\mathrm{f}} \\
{\left[{ }^{\circ} \mathrm{C}\right]}\end{array}$ & State of the wires \\
\hline 1 & 50.8 & 49.2 & - & - & $\begin{array}{c}\mathrm{n} . \mathrm{m} . \\
-15\end{array}$ & $\begin{array}{c}\mathrm{n} . \mathrm{m} . \\
+11\end{array}$ & $\begin{array}{c}\text { As received } \\
\text { quenching } 800^{\circ} \mathrm{C} / 1 \mathrm{~h}\end{array}$ & one-way shape memory \\
\hline 2 & 51.02 & 48.71 & 0.12 & 0.14 & $\begin{array}{c}-80 \\
-65 \\
-30\end{array}$ & $\begin{array}{c}-30 \\
-35\end{array}$ & $\begin{array}{c}\text { As received } \\
\text { quenching } 800^{\circ} \mathrm{C} / 1 \mathrm{~h} \\
\text { ageing } 500^{\circ} \mathrm{C} / 15 \mathrm{~min}\end{array}$ \\
\hline
\end{tabular}

n.m.- no measurable

\footnotetext{
$\bar{a}$ e-mail : henryk.morawiec@us.edu.pl
}

This is an Open Access article distributed under the terms of the Creative Commons Attribution-Noncommercial License (http://creativecommons.org/licenses/by-nc/3.0/), which permits unrestricted use, distribution, and reproduction in any noncommercial medium, provided the original work is properly cited. 
In the martensite state achieved by cooling below $\mathrm{M}_{\mathrm{f}}$ temperature (about $0^{\circ} \mathrm{C}$ ) the coils of the ring is open to an angle of 30 to $40^{\circ}$ and each coil of the ring is inserted through two incisions into one of the intestinal loops to be anastomosed. The procedure of inserting the clips into the bowles and its final shape is shown in Fig. 1.

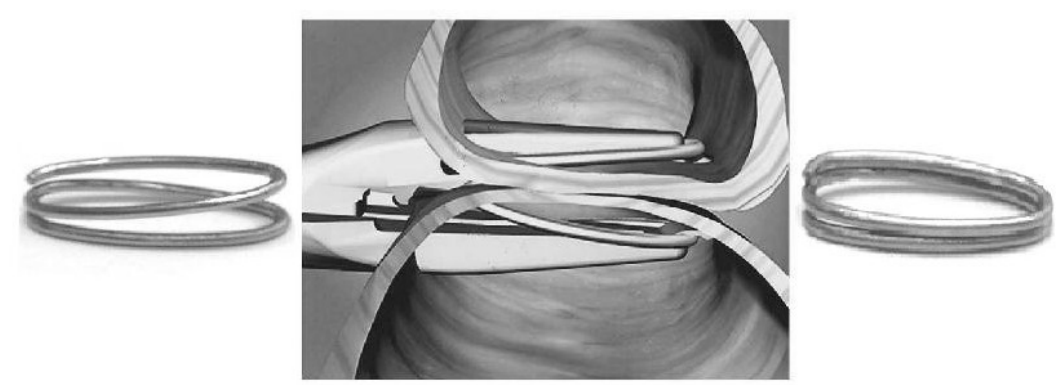

Fig.1. Model illustrate the side-to side bowels anastomosis procedure by means of shape memory clip.

During the reverse martensitic transformation by warming the ring by body heat the two coils join together and creates the compressive force on the connected bowel walls. The continuous compression of the bowel walls entrapped by the clip leads to necrosis within 5 to 10 days. The two coils of the device detaches itself and is expelled with the feces. New natural scar tissue is formed along the necrotic perimeter during the period of necrosis, resulting in a uniform perfectly anastomosis.

The studies were carried out on wires supplied by SMATEC- company (Belgium). The wires were heat treated to achieve the $\mathrm{M}_{\mathrm{s}}$ temperature below $0{ }^{\circ} \mathrm{C}$ and $\mathrm{A}_{\mathrm{f}}<30^{\circ} \mathrm{C}$. The compression of the device was achieved by using the body heat of the patient.

\section{Results}

Fig. 2 shows the shape recovery curve for a formed clip. The compression force of clip can be varied by formation procedure in the range between $400 \div 1400 \mathrm{G}$.

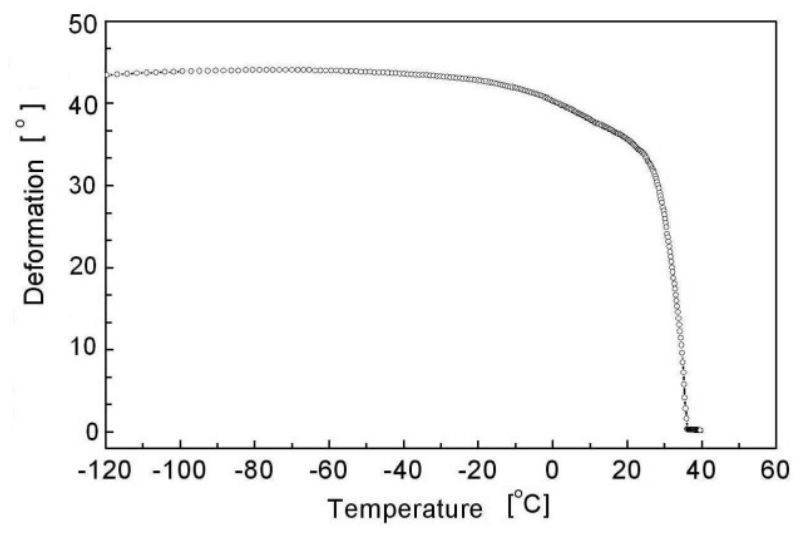

Fig. 2. Shape recovery of a clip.

It is well known that the two-way memory effect TWME is not an inherent property and requires thermomechanical training [8]. To obtain the TWME it is necessary to generate some dislocation arrays and residual stress field induced by: single deformation, aging under external stress and thermomechanical cycling [9].

The high value of TWME respond and a uniform compression force on the whole perimeter of the double coil ring was obtained by combining three methods of it generation: deformation the two ends of the coil in the parent phase, constraining ageing of the coil and thermomechanical cycling. The opening gap of the clip induced by TWME using combine methods versus temperature is shown in Fig. 3. The two-step on the heating curve is the result of overlapping the retransformation sequence: $B 19^{\prime} \Rightarrow R \Rightarrow B 2$ at a narrow range of temperature. The value of the induced opening gap of the clip is $7 \mathrm{~mm}$ and the compression force is equal $10 \mathrm{~N}$. 


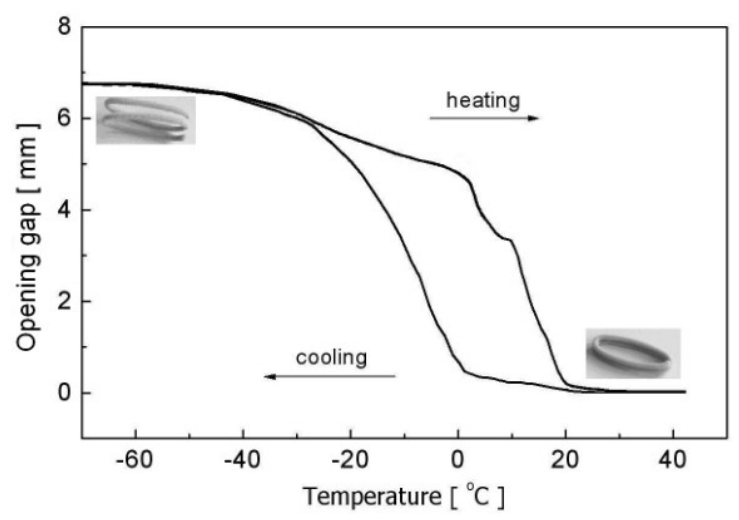

Fig. 3. Characteristic of a clip with TWSM induced effect.

The ageing of alloy 2 introduced by TWSME generation causes the change of the transformation sequence from $\mathrm{B} 2 \Leftrightarrow \mathrm{B} 19^{\prime}$ for the quenched state to the transformation through the R-phase as shown on the DSC curves after ageing at $450^{\circ} \mathrm{C}$ (Fig. 4).

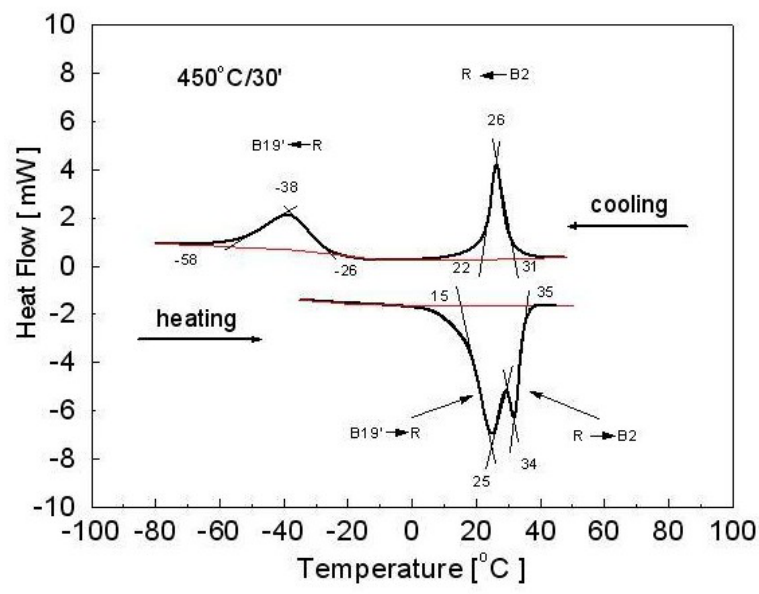

Fig. 4. DSC curves recorded during cooling and heating of alloy 2 after aging at $450^{\circ} \mathrm{C}$ for 15 minutes.

Before the sterilization by irradiation, the clips have undergo the surface passivation into an autoclave at $134^{\circ} \mathrm{C}$ for 30 minute in order to improve their biocompatibility. The first testing of the clips were carried out on pig bowels and allowed the second step - their clinical applications as shown on Fig. 5 [10]

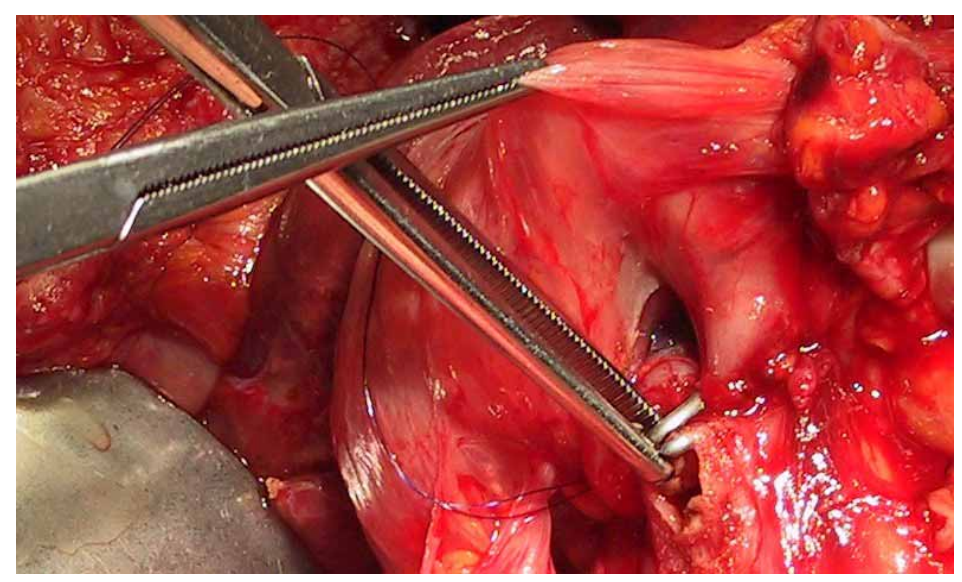

Fig. 5. Clinical application of CAC for joining of bowels. 


\section{Conclusions}

- A technology was elaborated which allows production of clips for compression anastomosis.

- Two-way shape memory effect was induced in the CAC which allows to achieve $7 \mathrm{~mm}$ opening gap during cooling and a uniform compression force on the perimeter of the coil up to $10 \mathrm{~N}$.

- The clinical studies shows that the shape-memory clips for CAC are easy to apply, shorten the time of operation and reduce the cost of operation.

\section{Acknowledgment}

The authors are grateful to the Polish Ministry of Science and Higher Education for financial support into the frame of the project: PRB - /RJP3/06.

\section{References}

[1] R Aggarwal, A. Darzi, J Am Coll Surg 20, 965 (2005)

[2] I.L. Nudelman, V. Fuko, S. Morgenstern, S. Giler, S. Lelcuk, World J Surg 24, 874 (2000)

[3] V.E. Giunter et al. Nikielid Titana-medicinskij material novogo pokolenia. Tomsk, Izd. IMC 2006 (in russian)

[4] I.L. Nudelman, V. Fuko, F. Graif, S. Lelcuk Am J Surg 183, 697 (2002)

[5] I.L. Nudelman, V. Fuko, N. Waserberg, Y. Niv, M. Rubin, A. Szold, S. Lelcuk, Am J Surg 190, 434 (2005)

[6] A. Szold, Min Inv Ther 17, (3) 168 (2008)

[7] L. Monasevitch, N.B. Dov-Laks, N. Tyagunov, A. Perle, M. Arad, S. Lelcuk., D. Kopelman, A. Szold "Design principles of shape memory devices for compression anastomosis in the digestive system" Int Conf on Shape Memory and SuperelasticTechnologies, Pacific Grove-USA May 7-11, edited by B. Berg and M.R. Mitchell and J. Proft (ASM Int Materials Park, Ohio, 2008), p. 703.

[8] E.P. Ryklina, S.D. Proroshkin, I.Yu. Khmelevskaya, A.A. Shakhmina, Mater Sci Eng A 481-482, 134 (2008)

[9] K. Wada, Y. Liu, Mat Sci Eng A 481-482, 166 (2008)

[10] P. Lampe, K. Kuśnierz, D. Zhavoronkov, H. Morawiec, Polish J Surg 80 (6), 306 (2008) 